\title{
THE BUSINESS OF PARADOX: CLASSIC METHOD SUSTAINABLE
}



University Mendel University in Brno, Brno, Czech Republic

\begin{abstract}
:
Purpose: The basic paradox and research question in the beginning was the combination of luxury wine marketing of sparkling wines and sustainability. The main research objective is to define and evaluate the benefits of establishing and developing wine cluster for sustainable sparkling wine producers. Very important research objective is how to increase motivation to start new businesses providing sustainable development in the region.

Design/methodology/approach: The most of all the research and scientific resources were obtained with cooperation of Austrian Wine Producers Associations and specialised academic experts at the Universities in Austria. The wine industry in Austria has experienced dynamic development and intensive cooperation in wine clusters has led to worldwide fame and significant export successes. Examples, principles and models of successful cooperation within associations and clusters can lead to a generalization of the theoretical approach and inspiration for other clusters in neighbouring countries. The special emphasis to innovative approaches and principles leading to sustainable development in cluster research. The source of research are interviews with cluster managers, and research among winemakers and winegrowers. Further research of trends in target markets.
\end{abstract}

Findings: The values relating to the environment and society are of particular importance in the eyes of the consumer, who acts as a responsible citizen. Moderate regular drinking of classic sparkling wines creates space for education in the areas of sustainability and circular economy of their producers. Sustainability, Certified organic wine, Certified biodynamic wine, Natural wine or raw wine have become part of complex modern business management and marketing of wine clusters specializing in the production of classic sparkling wines. Findings of the research is devoted in detail to the organization the CIVC (Comité Interprofessionnel du Vin de Champagne), the Comité Champagne is trade organisation representing interests of independent producers (vignerons) and Champagne Houses. Champagne to be a fully sustainable region by 2030. The point of view of the organization of a new appellation system for sparkling wines in the Czech Republic is examined in detail with the introduction of the highest Austrian sparkling wine category Sekt G.U. (PDO). Six years ago (2015) local producers set the course for Austrian Sekt with a protected designation of origin and certified quality has been instantly recognizable for consumers via the three quality classes - The Asutrian Sekt G.U. Quality Pyramid - of Klassik, Reserve and Grosse Reserve. The inspiration for the intensive cooperation of individual producers is the Method Cape Classic association in South Africa, whose model of operation is excellent in wine tourism and especially in the areas of cooperation on innovation and new sustainable processes.

Research limitations: The suggestions for future research is possible in new emerging Moravia Classic Method association created in this year 2021. The identified limitations in the research processes are influenced by pandemic crisis COVID19 and related declines in producer turnover and wine sales throughout the wine world.

Practical implications: The implications for organisation in cluster practice, applications and consequences are identified by three examples of clusters (France-CIVC, South Africa - MCC, Austria - Sekt G.U.). All examples of cluster organisation is going to responsible sustainable outcomes.

https://doi.org/10.11118/978-80-7509-820-7-0172 
Key words: wine clusters, paradox luxury and sustainability, CIVC, MCC, Quality Pyramide

\section{Introduction}

Wine production before the Velvet revolution (before 90's) in the Czechoslovakia was focused on quantity and not to allow the development of specialized categories with high value added such as classic method sparkling wine. The whole wine sector subsequently recorded a very slow development of only quantitatively orientation towards production quality and focusing on originality associated with the uniqueness. There are new projects to promote wine with high value added after the beginning of the new millennium.

The permanent trend of development and market growth were the starting potential for the creation of a completely new system of wine trails in South Moravia region. Wine production area with $96 \%$ of vineyards is mainly located in this region, southeast part of the Czech Republic. South Moravia is a traditional wine-growing region. Wine production and the associated culture is next to the natural and historical attractions one of the main attractions to visit this site. Tourism and the service sector in general have progressive growth in recent years. Winery, wine and wine tourism are the flagship of South Moravia. 


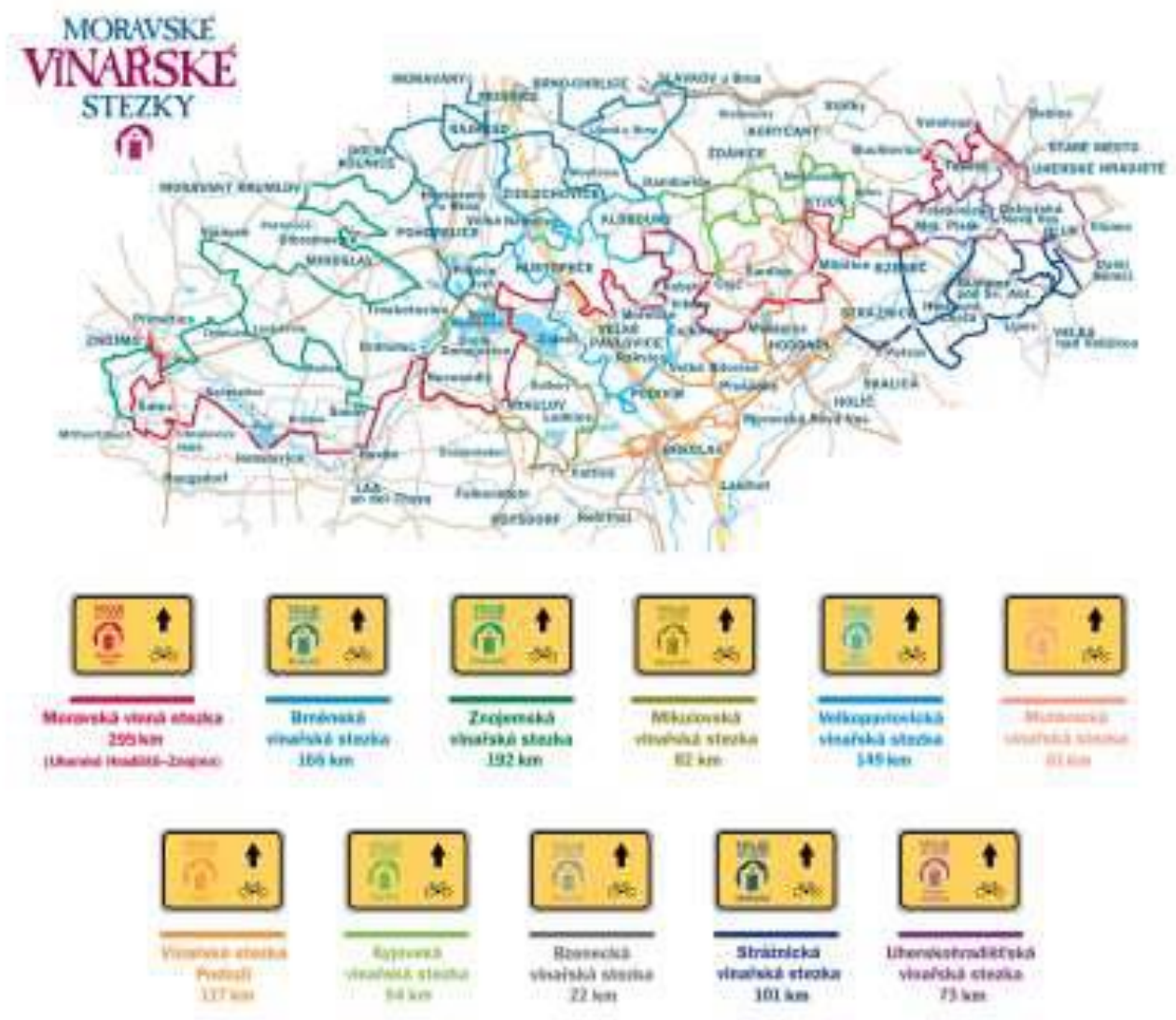

I: Map of Moravian wine trails in the starting plan (Partnership, 2016)

The project Moravian Wine Trails started with activities of Partnership Foundation and for the first time clearly determined the concept of wine tourism and to name needed infrastructure. When we analyzed the starting process of management of project we could find separately "modules" that could be implemented gradually and separately, without losing functionality and threatened the possibility implement other modules.

There are mainly four modules in the beginning of project: MODUL A - a network of cycle paths:

- total plan of 11 routes connected in a network of 10 regional trails,

- one main backbone trail with a total length $1200 \mathrm{~km}$;

MODUL B - the development of services for cycling;

MODULC - creating a total product and components of wine tourism;

MODUL D - on promotion and marketing. 
There was in terms of methodology procedures were such as surprising the first of the modules was implemented marketing of trails. So Moravian Wine Trails map was published in the year 2000, or a year before showing the first tracks in the field and 3 years ago marking the completion of the entire network of trails in the country. The services and marketing tools for its development, Project with great vision and ambition proposed the creation of a network of cycle paths, linking all major winegrowing village, the location of vineyards and monuments South Moravian region, extending to "Uherskohradišt'sko" belonging to Zlin Region. Even as the creation of regional tourist products getting ahead of its time in 1998, when there were regional associations of municipalities. They have been established or region. Invitation to collaborate on this project addressed 310 wine villages and farmers, at that time, mostly hidden then behind the curtain of gray economy.

Development of wine tourism is important for the South Moravia region, southeast part of the Czech Republic. In addition, the wine tourism brings revenue side entities operating in agriculture, thereby increasing the standard of living of the population, also brings to the region more jobs and higher income. Tourism and the service sector in general have progressive growth in recent years. Winery, wine and wine tourism are the flagship of South Moravia. In the segment of wine tourism is a dynamic development and is certainly not true that tourists come for winemakers only on so-called "wine cellar evening". Tourists as wine lovers are also interested in the possibility of tours vineyards, own work in the vineyard, and training in the production of wine in the cellar.

The research project follows the development of the regional associations of small and medium-sized wineries cooperating in system for appellations Vína Originální Certifikace (VOC). There are successful forms of wine tourism cooperation in wine clusters -in the world, which can serve as a source of inspiration for the growing cluster initiatives in the Czech Republic.

Cooperation in regional associations, which leads to the creation of new offer of services include wine tourism is strategic business decision, leading to a strengthening effect on the negotiating dynamics in the industry. As stated by Porter (2007) the reason why companies are successful or are falling, the question is in the center of strategy. Porter (1990) was the first in their work using the concept of cluster in the context of wine production, namely on the basis of research work related to wine producers in California, specifically in the Napa and Sonoma Valley. There was started a regional research activities to study winemaking. Before wine from California in the eighties of the last century broke on the export to all over the world, wine production has undergone great development in quality and quantity. This development has attracted some new producers to enter into this industry and also caused the development of other related industries such as wine tourism.

Furthermore research of clusters uniting producers of vine and wine published by Müller and Summer (2005). Formation of wine cluster in New Zealand is researched by Dana and Winstone (2008), in the South Africa by Davidson (2009) and in Chile by Visser (2004). 
Aylward (2008) describe the differences in the two types of Australian wine cluster. South Australian Cluster, which can be described as innovative and organizational type cluster in Victoria and New South Wales.

There are also publishing researchers in the Czech Republic, who engaged in the initiatives of local and regional farmers which joint together to market, e.g. Lošták, Kučerová, Zagata (2006).

Place-based marketing and cooperation winemakers appears frequently in publications from Mitchell and Hall (2006, 2012). The institutional theory and resource based-theory of clusters in wine tourism industry researched also Grimstad (2011).

\section{Material and methods}

To achieve the objectives of the study and an overview of the target market segments requires analysis of the behavior of consumers and providers of wine tourism, which was done by the method of marketing research. For primary data collection system was used RELA (Research Laboratory), which was created in collaboration with the Institute of and Marketing, Faculty of Business and Economics, Mendel University in Brno. Primary data were then processed by MS Excel and Statistica. Results are presented in the form of tables and graphs.

Service providers wine tourism were addressed questionnaires electronically. The source directory of certified equipment was provided by the National Wine Centre. Of the 701 facilities for providers of wine tourism in the wine region of Moravia 674 providers responded. Of the 2400 respondents tourists - wine tourism consumers - responded to the questionnaires 873. Questionnaire was distributed to a consumer in the form of an interview by interviewers and electronically by e-mail. Research at consumers focused on finding the perceptions of consumers on the concept of wine tourism.

In order to identify multiplying effects of wine tourism cluster can use the following macro-analytical tool that recommends Porter (1998):

$$
\text { Localization quotient }(L Q)=\frac{\frac{x}{X}}{\frac{y}{Y}}
$$

LQ - location quotient of employment in the region

$\mathrm{x}-$ the number of employees working in the sector in the region

$\mathrm{X}-$ total number of employees in the region

$\mathrm{y} \quad-$ the number of employees working in the sector in the state

$\mathrm{Y}-$ total number of employees in the state. 
Potential for regional clusters is where there are groups of related industries with LQ greater than 1.

To achieve the goals of this research is designed concentration quotient, which is indicating the proportion of vineyards in the region and the total area of vineyards. This concentration factor is calculated for the association of VOCs in the Czech Republic.

$$
\text { Concentration quotient }(C Q)=\frac{\frac{a}{A}}{\frac{b}{B}}
$$

CQ - concentration factor area of vineyards in the region / in a certain area for the establishment of an association of wine growers or cluster

a - the number of vineyards in the region certified by the association rules (ha)

A $\quad-$ total number of vineyards across the region (ha)

b - the number of vineyards of the all associations (ha)

B $\quad-$ the total area of vineyards in the country (ha).

Sources of secondary data are The National Wine Centre, Valtice; Wine Fund of the Czech Republic; Confederation of Commerce and Tourism; Association of hotels and restaurants; CzechTourism; Tourist information centers in South Moravia region; Destination Agencies of the tourist areas.

\section{Results and Discussion}

For further research, it was important to make a categorization of events and services. Based on consultations with experts were chosen individual criteria and design events categorization - the type of markets, festivals, wine tasting with typical local products and special gastronomy in conjunction with wine. Selection of current events is conducted with the aim to create an overall picture of "gastronomic and viticultural peculiarity" of the region of South Moravia.

Selected events meet the priority criteria:

- The focus thematic event for wine and regional products, gastronomic speciality products

- Regional growers, breeders, farmers

- Gastronomic specialities with traditional recipes

- Regional character, to products originating in the region South Moravia respectively, with an overlap in neighboring regions while respecting the wine region Moravia.

The above services will be followed by others which are not directly service designed exclusively for wine tourism, but can also serve its consumers. For example it is possible to rent bicycles or their storage and transportation. Is not only tourists who want to go on a tour of the wine trails, but others who have different objectives. 
They're also the possibility to visit historical and cultural sites in the area and related information services. These are main destination for tourists, but for wine tourism may serve as an accompanying program. Likewise, national parks, protected landscape areas and natural attractions are indeed independent tourist destination, but the wine tourism can serve as additional services. Another group of supplementary services are the activities in the area - golf, tennis, windsurfing, fishing, water sports and more.

Evaluation of Satisfaction wine tourism providers with the support and promotion of wine tourism implies a prevailing opinion on the adequacy of support providers wine tourism. A majority of the respondents, namely $55 \%$ of the promotion of the wine tourism in the Czech Republic as sufficient, or rather sufficient. On the contrary, as totally inadequate by $10 \%$ of respondents assessed. $35 \%$ of respondents believe that wine tourism rather insufficient support. We can say that the prevailing positive rating support wine tourism, but positive assessment does not exceed the rating too negative. The proposals to improve support providers primarily suggested more advertising on the Internet and on television. Also suggested holding more wine events. Would welcome further tax cuts and cut red tape. In the field of wine tourism providers suggest more support from the various regions and cities. They would welcome the issue of maps, information brochures, information centers and improve the functioning of signs in the wine, which informed about the possibilities and especially the specific wine tourism providers in the area. Importance for the development of wine tourism, according to providers also improve transport infrastructure in the regions, particularly road repairs lower classes, and also a greater number of car parks and rest areas in the region. Other proposals concerned the involvement of travel agencies and tourist authorities CzechTourism, which should further promote wine tourism driveway.

The most preferred form of advertising on television and internet advertising. You would like to see almost $72 \%$ of respondents. Next in line is advertising in the press, would prefer that $54 \%$ of respondents. Followed by outdoor advertising, which would be welcomed by almost $35 \%$ and radio advertising with $30 \%$. Alternative media, such as city light displays, benches and public transport stops, elected by $28 \%$ of respondents. Another form of promotion suggested 13\% of respondents.

Providers often suggested cooperation between the National Wine Centre Wine Fund and with travel agents. They would welcome the creation of packages consisting of offering more certified equipment and also to travel agencies more focused on mediating domestic and wine tourism driveway and not on the exit wine tourism. With this and other proposals related to Tourism focused more on the region of South Moravia and wine tourism. Another common theme was greater collaboration among the various actors in the region. And while uniform treatment of wine tourism in the regions. Not only within the region but generally the entire southern Moravia providers should welcome greater mutual awareness of the organized events. It seems reason to avoid collision terms and consumers can visit more actions.

In addition, providers should welcome more wine fairs and exhibitions in the Czech Republic and also more options common presentation of Moravian and Czech 
wines abroad. Providers also mentioned the possibility of using "smart phones" via mobile applications related to wine tourism.

Research at consumers focused on finding the perceptions of consumers on the concept of wine tourism. Responses are divided into 14 categories.

As shown in the enclosure, for most respondents, $16.39 \%$, means wine tourism wine tasting combined with a stroll through the vineyards in South Moravia. Fewest respondents that concept associated with a specific wine events. In addition, respondents often associate this term with the term "trip or traveling for wine," or have it linked to journey by bike or on foot along the southern Moravia. With cycling to wine tourism combines $9.84 \%$. Hiking through the vineyards and the cellars imagines $9.02 \%$ and the same number is associated with this term vision of the program with sleeping for wine cellar. Hiking in the wine-growing regions and exploring new places (without wine consumption) conceives of $6.56 \%$ of the respondents. Similarly, $6.56 \%$ of respondents did not know what to imagine under this term. Less frequent responses were then vintage tasting and demonstration of production and wine trails and wine cellars. And overall the most comprehensive list, a wine events, visit wine equipment, cycling, imagine just $2.46 \%$ of the respondents.

Source of information on wine tourism is mapped according to research carried out in the picture No.7. Most, nearly $60 \%$ of respondents, the wine tourism learned from the Internet. Another major source of respondents were familiar. Since then learned about wine tourism $48,36 \%$ of respondents. The press and television learned about wine tourism $18,85 \%$, from family members and from $7,38 \% 6,56 \%$ radio. From other sources for wine tourism learned of $7.38 \%$ of the respondents

Based on the results of the calculation of the coefficients for the determination of the potential for establishing a cluster and the objective situation in the European market in wine was established design of the cluster, which will be based on the principle of integrated VOC three regions (Pavlovice, Mikulov, Znojmo) with CE South Moravia. The proposed cluster has high coefficients of LQ and CQ (chart II). Due to the relatively high concentration of production resources has potential for competitiveness and clear identification of consumers in the domestic market, and also by Slovak wine market in Central Europe. The scope of activities in the first phase, coordination of services recommended wine tourism in Southern Moravia. 
II: Localization (LQ) and Concentration Quotients (CQ) VOC

\begin{tabular}{lcc}
\hline Wine Region & LQ & CQ \\
\hline VOC Znojmo & 1.02 & 1.51 \\
VOC Modré Hory & 1.30 & 2.46 \\
South Moravia & 2.26 & 2.81 \\
\hline
\end{tabular}

\section{Conclusion}

Based on the results it can be concluded that the interprofessional association VOC Czech Republic meets the conditions for a cluster. Localization quotient was calculated on the value well above the minimum value. A new alliance of wine producers of VOCs in the Czech Republic also has a concentration quotient larger than a minimum value, and thus fulfills the opportunity for the formation of the cluster.

The plan to create a wine cluster was proposed to establish cooperation between the newly emerging associations of VOC at three sub-regions of South Moravia, in order to achieve competitive advantage in wine tourism.

This paper analyses the potential for wine tourism development and creating a plan for newly formed strategic alliance coordinating services offer all wineries in the region. This study describes the potential to offer services and products of wine growing areas in South Moravia region in the southeast part of the Czech Republic, suitable for promotion offers wine tourism destinations and services. To achieve the objective of the paper was conducted marketing research data collection and mapping current events and activities taking place in the wine-growing region of Moravia, promoting or offering specific local products and services associated with gastronomy and wine.

Based on the results it can be concluded that the interprofessional association VOC Czech Republic meets the conditions for a cluster. The plan to create a wine tourism cluster was proposed to establish cooperation between the newly emerging associations of VOC appellation at three sub-regions of South Moravia, in order to achieve competitive advantage. 


\section{References}

1. AYLWARD, D., 2008: Research and development structures within the Australian wine industry: organizational implications, global challenges and a changing of the wine culture, School of Managemen and Marketing, University of Wollongong.

2. DANA, L. P., WINSTONE, K. E., 2008: Wine cluster formation in New Zealand: operation, evolution and impact. International Journal of Food Science \& Technology, 43,

3. DAVIDSON, N., 2009: The South African Wine Cluster. Harward Business Review: Institute for Strategy and Competitiveness, $30 \mathrm{p}$.

4. GRIMSTAD, S., 2011: Developing a framework for examining business-driven sustainability initiatives with relevance to wine tourism clusters. International Journal of Wine Business Research, 23, 1: 62-82. ISSN: 1751-1062.

5. HALL, C. M. M., \& MITCHELL, R., 2012: Wine marketing. New York: Routledge, 345 p. ISBN: 978-0-7506-5420-3.

6. LOŠŤÁK, M., KUČEROVÁ, E., ZAGATA, L., 2006: Encouraging Collective Farmers Marketing Initiatives (COFAMI).

7. MITCHELL, R., \& HALL, C. M., 2006: Wine tourism research: the state of play. Tourism Review International, 9, 4: 307-332. ISSN: 1544-2721.

8. MÜLlER, R. A. E., SUMMER, D. A., 2005: Clusters Of Grapes And Wine. American Agricultural Economics Asssociation, Providence.

9. PORTER, E. M., 1990: Clusters and the New Economics of Competition. Harward Business Review, 52 p. Available at http://isites.harvard.edu/fs/docs/icb.topic1188431.files

10. PORTER, M. E., 2007: Towards a dynamic theory of strategy. Strategic management journal, 12, S2: 95-117. ISSN: 0143-2095.

11. VISSER, E. J., 2006: The importance and quality of governance in the Chilean wine industry. GeoJournal 65, 3: 177-197. ISSN:0343-2521.. 